\title{
EDITORIAL
}

\section{Changing of the Guard, 2014}

\author{
Kathleen Y. Haaland \\ New Mexico VA Healthcare System and University of New Mexico
}

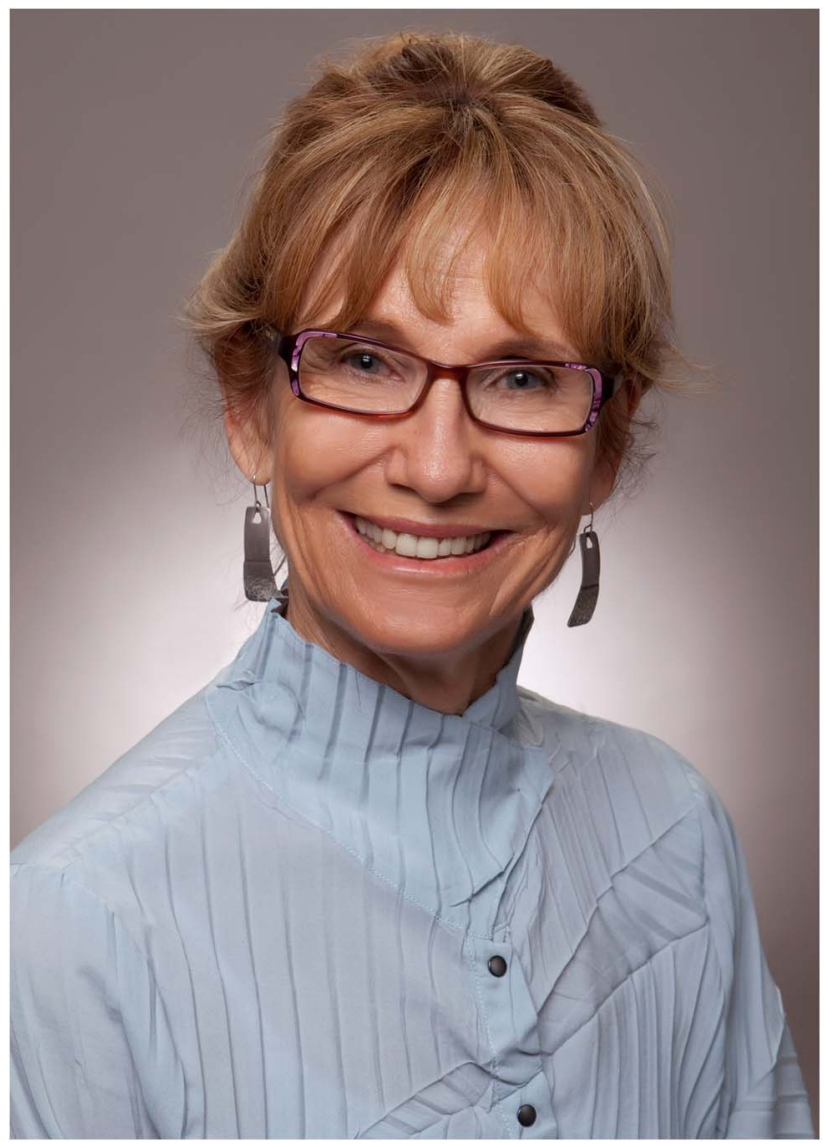

I wrote this same editorial when I became editor-in-chief of JINS (Haaland, 2004). I was optimistic about the Journal then, and now after 9 years as editor, I am even more optimistic. The structure of the Journal's editorial board continues to be a major strength with an Editor-in-Chief who assigns manuscripts to the Associate Editors and is ultimately responsible for the final decision, Associate Editors who are action editors and provide decision recommendations to the Editor-in-Chief, and Department Editors who oversee Reviews and Dialogues, Symposia, and Book reviews. I believe this structure is ideal for ensuring that manuscripts will be given the best reviews by experts in the topic of the manuscript and ensuring that the Editor-in-Chief has the best possible advisors who represent the incredible breadth of the INS membership and the field.

I will be stepping down from the JINS Editor position at the end of 2013. As most of you know, Stephen Rao has been selected by the INS Board to be the new Editor. Dr. Rao, who was an Associate Editor of JINS before he became Editor of Neuropsychology, has a wealth of editorial experience and is a well-respected clinician and researcher. We have been working together over the past few months to make the editorial transition as seamless as possible. I know that JINS will be in good hands, which makes it easier to leave the editorship that has so dominated my life for the last 9 years.

Dr. Rao will begin his tenure on January 1, 2014, and while the JINS editorial office in New Mexico will be working normally until December 31, 2013, all new manuscripts will be managed by Dr. Rao and the new editorial board as of January 1. Manuscripts already in the review process will be managed by me and my Associate Editors until March 31, 2014.

It has been a great honor to be the Editor of JINS. It is a job that is constant no matter what you are doing or where you are, although I have to thank Keith Yeates for shepherding JINS while I was trekking in Nepal in 2010. Despite its constancy, it has been extremely rewarding. In my view, it is another way to contribute to the development of the field, especially in terms of invited reviews, special series, and symposia. I have particularly enjoyed seeing the breadth and depth of research being conducted, and the generosity of reviewers has been inspiring. I believe that JINS reviews are some of the best in terms of their detail and constructive suggestions, and although I've heard my share of grumbling about this, most authors seem to agree. I hope that you're one of them. Finally, I hope that authors believe that they have been treated fairly because that was one of my most fervent goals.

I think the Journal is in a better position than it was in 2005, and Igor Grant, the founding editor, had done an excellent of starting the Journal and building it until 2005. We have made many changes in JINS through the work of the senior editors as well as Donna Epler, my able editorial 
assistant, the Cambridge University Press editor and staff (Jon Spielburg, Meredith Clark, and Susan Soule), and the INS Publication chair, Sureyya Dikmen. These changes include the new cover (introduced in Volume 11, Issue 1, January 2005), electronic submission, significant decreases in review time (first decision: 4 weeks), electronic publication within approximately 2 months of acceptance and print publication within approximately 3 months of acceptance, editorial assistance for English editing through John Woodard's INS editorial committee, continuing education credits for selected JINS papers, development of the first virtual issue which was coordinated by Sureyya Dikmen and Jennifer Vasterling (Complexities of mild traumatic brain injury and PTSD) and which included articles that had been previously published in JINS but through the virtual issue were made available to non-members of INS, addition of Special Series to supplement our annual symposium, addition of the short focused review to provide readable reviews that are accessible to the expert and non-expert in an area, the ability to download JINS manuscripts to Kindle (2012) and more recently to Android, and an increase to 10 issues per year with associated page increases. Additional developments over the past 9 years include doubling the number of submitted manuscripts to approximately 360 per year, slight increases in the rejection rate (currently approximately $75 \%$ ), and better promotion of selected JINS articles including periodic email campaigns to make JINS temporarily available to select individuals (e.g., non-members who attend the INS conference).

I could not have done this work, especially for 9 years, without the help of the senior editorial board, the consulting editors, and all of the many reviewers. The Journal could not operate as it does without them. I want to take this opportunity to thank the current Senior Editorial Board, including the Associate Editors (Mark Bondi, Jennifer Manly, Skye McDonald, Steve Nadeau, Yaakov Stern, Yana Suchy, Keith Owen Yeates) and Department Editors (Ida Sue
Baron, Sterling Johnson, and Mary Pat McAndrews). I want to especially recognize Yaakov Stern, Jennifer Manly, and Ida Sue Baron who have been on the Editorial Board for the entire 9 years, and who have contributed enormously throughout that time. We have had a total of 9 other Senior Editors since 2005 who have resigned for various reasons (Associate Editors: Gregory Brown, Thomas Hammeke, Kimford Meador, Stephen Rao, H. Gerry Taylor, Eli Vakil, and Department Editors: Russ Bauer, Bruce Crosson, and Mieke Verfaellie). I have appreciated all of these senior editors past and present for their scientific expertise, sound judgment, and ability to see the possibilities in manuscripts that required significant revisions before being ultimately accepted. While being Editor-in-Chief of JINS takes approximately $20 \%$ of my time, I suspect that the Associate Editors spend at least $10 \%$ of their time working on JINS. They deserve our thanks for their work, because they are constantly bombarded by manuscripts that require their opinion, they must wrestle with sometimes very difficult decisions, and they receive minimal concrete reward. Please thank them.

Finally, thanks to the INS Board of Directors for appointing me to be Editor-in-Chief of JINS. As you can tell, it has been a very rewarding experience for me, and I look forward to seeing the Journal continue to develop and become the most widely read and cited neuropsychology journal under the capable hand of Stephen Rao.

\section{ACKNOWLEDGMENTS}

The contents do not represent the views of the Department of Veterans Affairs or the United States Government.

\section{REFERENCE}

Haaland, K.Y. (2004). Changing of the guard. Journal of the International Neuropsychological Society, 10, 929-930. 